\title{
Adolfo Rivadeneyra, un diplomático español al servicio del estudio y del viaje por Oriente
}

\section{Fernando Escribano Martín}

Arbor CLXXX, 711-712 (Marzo-Abril 2005), 789-804 pp.

Adolfo Rivadeneyra fue un diplomático del siglo XIX que unió su profesión a su gran pasión, el Oriente, del que se convirtió en un gran especialista. Desde distintas instituciones, y a través de diversas actuaciones, pretendió introducir la ciencia del Orientalismo en España. Fue autor de dos libros de viajes en los que, además de narrar algunos periplos realizados, introduce estudios e ivestigaciones que hoy catalogariamos como pertenecientes a distintas ciencias. Sólo su temprana muerte, y la falta de apoyo institucional, le impidieron mayores triunfos intelectuales, pero aún así su brillante trabajo no puede pasar desapercibido.

La figura y la obra de Adolfo Rivadeneyra es equiparable a otras personalidades europeas que, contemporáneamente, descubrían y estudiaban la historia del Oriente, en una época en la que múltiples expediciones de estudio, descubrimiento y ocupación iban sentando las bases del Colonialismo que comenzaba ya y se desarrollaría en breve. Este colonialismo en ciernes, en la zona que nos interesa del Oriente Próximo, corrió paralelo al nacimiento de la ciencia del Orientalismo, de la cual participó Rivadeneyra por conocimiento, pero sobre todo dando pasos para su introducción en España a través de distintas vías, incluida la realización de trabajos al respecto que hoy descubrimos en su verdadera importancia. Otra vía fue la de crear o mejorar las bases culturales que favo- 


\section{Fernando Escribano Martín}

reciesen ésta y otras ciencias, en una labor compartida con otros compañeros de intenciones, y a los que no se les dió el apoyo necesario, completamente justo, por otra parte.

Nuestro protagonista nació el 10 de abril de 1841 en Valparaíso, Chile. Era hijo del editor Manuel Rivadeneyra (1805-1872) y de Nieves Sánchez y Riquelme. Manuel Rivadeneyra había marchado a América para conseguir fondos con los que continuar su magna obra, la Biblioteca de Autores Españoles. En Chile, además de fundar El Imparcial y realizar otras actividades editoriales, conoció a la que fue su mujer, y allí nació su primer hijo, Adolfo. Su segunda hija, Manuela Rivadeneyra, muy importante en la vida y en la herencia de sus padres y de su hermano, nació en Madrid en julio de 1854, y alcanzó a vivir hasta agosto de 1945 .

Cuando Adolfo tenía siete años volvió la familia a España, y continuó éste su formación en el colegio de Masarnau y en el Seminario de Vergara. Prosiguió después estudios en Francia, pues su padre consideraba muy importante la formación en idiomas, hasta alcanzar a acabar la educación secundaria, y posteriormente comenzó cursos en la Universidad de Madrid para ser ingeniero.

Sin embargo, creo que ya movido por su amor hacia el Oriente, en diciembre de 1863 solicitó ser admitido en la carrera diplomática o consular, a ser posible en un destino en el Levante. Solicitud que le es prácticamente de inmediato aceptada, y es admitido como Joven de Lenguas en el consulado de Beirut.

La figura del Joven de Lenguas era utilizada por la diplomacia española para formar jóvenes en las lenguas, digamos no habituales, de los países donde había legaciones, y sin duda escogieron un buen alumno, pues en la instancia para ser admitido en la carrera diplomática ya decía conocer cinco lenguas vivas y la latina, y a lo largo de su vida llegaría a manejar hasta once. Entendía Rivadeneyra que para conocer un país era fundamental aprender su idioma, como haría en cinco meses con el persa, y así, como parte de su formación fue ingresado en el convento de Ain-Warka para aprender árabe. Los resultados que en cincuenta meses adquirió al respecto fueron calificados por el Cónsul General, Antonio Bernal de O'Reilly de asombrosos, y así se lo hizo saber en nota al Primer Secretario del Despacho de Estado. Fruto de estos trabajos fue el Estudio sobre el mecanismo de la lengua árabe que remitió a la Reina en septiembre de 1865, y que después incluiría en uno de sus libros. 
Adolfo Rivadeneyra, un diplomático español...

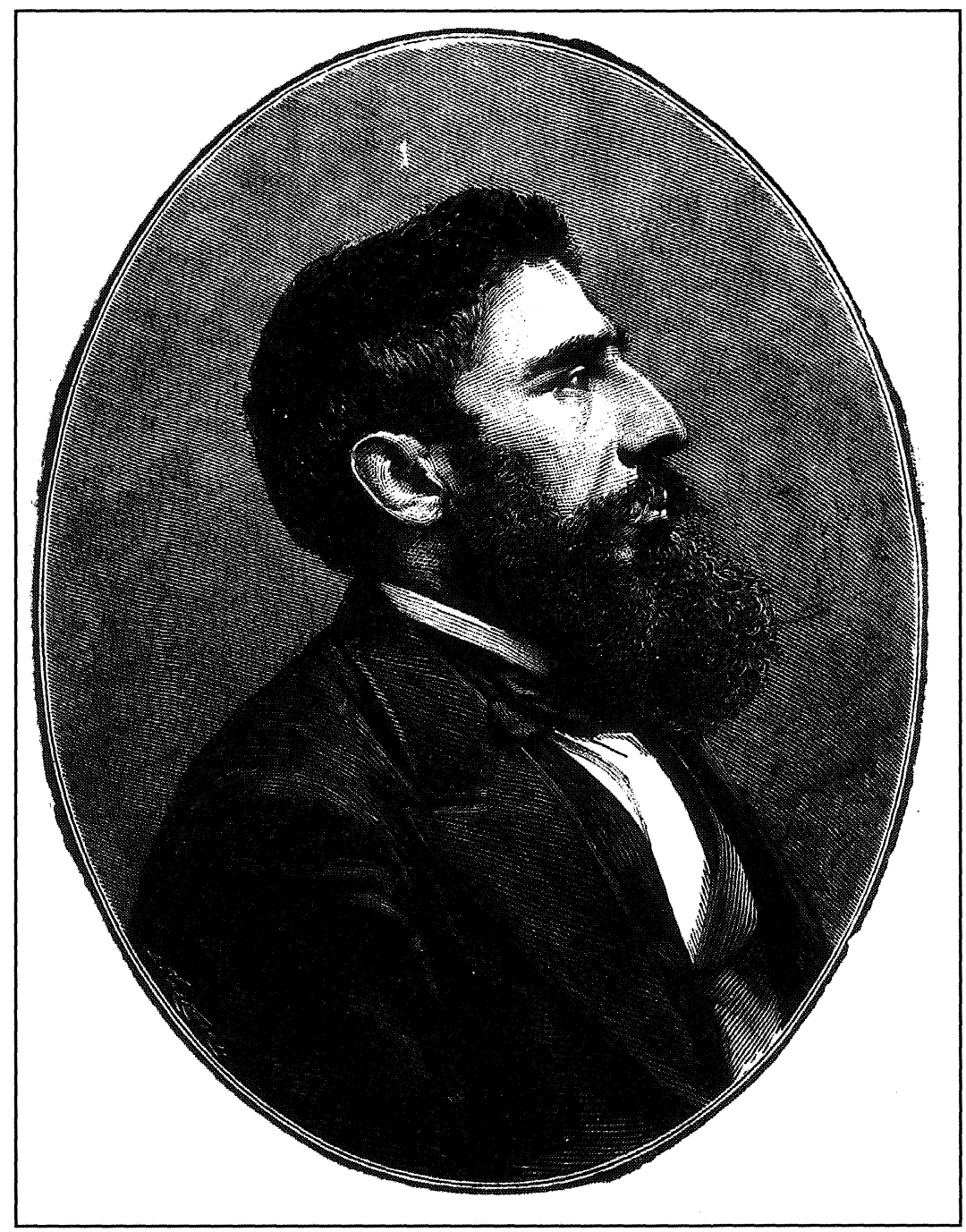

Figura 1. Adolfo Rivadeneyra 
No vamos a hacer en este texto un estudio de su carrera diplomática, a lo que sólo nos referiremos cuando tenga relación, muy importante por otra parte, con los viajes que realizó y escribió. Pero creo, sin embargo, que podemos señalarla siquiera en unas breves pinceladas. Ocupó como parte de sus funciones en el destino de Beirut ya señalado, por dos veces el Consulado General de Jerusalén, supliendo a los titulares. En diciembre de 1866 solicita licencia para volver a España a recobrar su salud, la cual le es concedida, y es nombrado, casi de forma inmediata, Vicecónsul en Beirut, cargo del que toma posesión el 5 de marzo, y que desempeñará hasta que el viceconsulado cese su actividad el 30 de junio de 1867.

$\mathrm{Su}$ siguiente etapa es el viceconsulado de nueva creación que desempeñará en la isla de Ceilán, con residencia en Colombo, y que dirige desde febrero hasta noviembre de 1868. El 25 de este mes se firma la orden del Gobierno que le traslada a Damasco, donde ha sido nombrado Vicecónsul en Turquía Asiática. Este nombramiento, del que tomará posesión el primero de agosto de 1869, en el trascurso del cual asistirá junto a Eduardo Saavedra a la inauguración del Canal de Suez, y que desempeñará hasta que es cesado en julio de 1870, dará lugar al viaje de un destino a otro que plasmará en el primero de sus libros, de Ceilán a Damasco.

Después de Damasco, su siguiente etapa profesional es la que le lleva a Teherán como vicecónsul, donde el Gobierno español de turno pretende explotar las posibilidades económicas y comerciales, y para cuya dirección elige uno de los mayores especialistas españoles en Oriente, nuestro protagonista, y le destinan al lugar que siempre soñó conocer. Rivadeneyra, como tantos otros funcionarios de su época, vivirá en primera persona la convulsa época política de esos años, donde a cada cambio gubernamental podía corresponder una remodelación de la Administración más o menos radical, donde los funcionarios, sin derechos adquiridos, sufrían la penosa figura del cesante que tan bien describe Pérez Galdós en Miau.

Desde abril de 1874 en que toma posesión de su cargo, hasta el 19 de agosto, permanece en Teherán, realizando informes previos y aprendiendo el persa, lo cual logra aceptablemente. Marcha en esta fecha a recorrer el país, cosa que hace durante prácticamente un año, regresando el 24 de agosto de 1875 . Solicita entonces una licencia para recobrar su salud en España, que le es admitida, y el viceconsulado viene suprimido el 9 de noviembre. Este destino, sus viajes y sus estudios, tomarán forma de libro, el segundo, del que después hablaremos, y que se tituló Viaje al Interior de Persia. 
Adolfo Rivadeneyra, un diplomático español...

El 9 de diciembre de 1878 es nombrado cónsul de segunda clase en Singapur, y diez días más tarde cónsul en Mogador (Marruecos), por lo tanto no llegó nunca a desempeñar el primero. El 8 de enero llega a su destino y desempeña su cargo hasta que le es concedida su renuncia en noviembre de 1879, parece que enfrentado al gobernador. Este será el último destino de una brillante carrera diplomática, truncada sin duda por una temprana muerte ( 6 de febrero de 1882 , con poco más de cuarenta años), que mereció diversos reconocimientos institucionales y que hizo de él uno de los mayores especialistas españoles del Oriente, tanto de su verdad contemporánea como de su historia. Una parte de estos saberes y conocimientos, pero sobre todo de sus inquietudes y de sus observaciones, los fue plasmando en sus libros y en sus conferencias, lo cual nos permite hacer un seguimiento de sus trabajos en pro de un mayor conocimiento del Oriente.

Esta labor diplomática que hemos descrito tendría sólo relativa trascendencia, al menos para nosotros, si no fuese por el papel en la difusión cultural, y sobre todo en favor del desarrollo del Orientalismo en España que llevó a cabo su autor, faceta que tuvo una estrecha relación con su labor diplomática.

El trabajo que Adolfo Rivadeneyra desarrolla en distintos campos culturales corre paralelo al de otros intelectuales españoles que pretenden y logran llevar a cabo investigaciones, estudios o expediciones de muy distinto signo similares a las que se están realizando en Europa. Personalidades, por citar sólo algunos relacionados con el Orientalismo, como Pascual de Gayangos, Francisco García Ayuso o Eduardo Saavedra realizan trabajos individuales o colectivos para crear instituciones, o para potenciar las ya existentes, que nos situasen en el campo científico al nivel europeo, superando el retraso de siglos. Al menos en el Orientalismo estos esfuerzos, que lograron hitos muy importantes, no tuvieron aparente continuidad, y hoy retomamos el legado que aquellos pioneros nos dejaron.

Así, Rivadeneyra introduce en sus dos libros estudios, testimonios e investigaciones que son similares a los trabajos que están desarrollando otros diplomáticos europeos que hoy consideramos los pioneros del Orientalismo, y que a veces incluso, gracias quizá a una mayor perspectiva, puede superar en profundidad. Además de estos libros, Rivadeneyra completó la Biblioteca de Autores Españoles de su padre, y en el tomo LXXI glosa un perfil biográfico del mismo. Participa de modo protagonista en la creación y constitución de la Sociedad Geográfica de Madrid, siguiendo modelos europeos, de la que es el Secretario de la primera Junta y primer conferenciante. Y fue nombrado también Socio Correspon- 
diente de la Real Academia de la Historia. Además, una parte importante de la colección de Oriente del Museo Arqueológico Nacional le fue donado o vendido al museo por Rivadeneyra, y cedió también al Estado importantes obras de arte vinculadas con su aventura.

En cualquier caso ya hemos comentado que no es el objeto de este texto ni trazar su biografía ni enumerar sus logros, aunque citemos una parte, sino el de recorrer, a través de sus libros, parte de los viajes que nos legó.

El primer libro de Rivadeneyra es Viaje de Ceylán a Damasco, Golfo Pérsico, Mesopotamia, Ruinas de Babilonia, Ninive y Palmira y Cartas sobre la Siria y la Isla de Ceilán, dividido en dos partes, y publicado en Madrid en 1871. En la primera va narrando el trayecto que desde Ceilán le llevó a Damasco (en cumplimiento del cambio de destino que hemos citado antes, y por llevar a cabo un viaje que su padre no pudo cumplir) a través de Bombay, Basra, Bagdad, Mosul, Diarbekir y Alepo. El décimo capítulo, que titula Las ruinas de Palmira, donde describe el viaje y las propias ruinas, viene dedicado a Eduardo Saavedra, que fue quien le propuso para Socio Correspondiente de la Academia de la Historia. Aprovecha también su estancia en Bagdad para dedicar un capítulo a la descripción de la ciudad, también de su historia, y otro a las ruinas de Babilonia.

Este capítulo, escrito in situ: Hilleh, $1^{\circ}$. de julio de 1869, tiene para nosotros el valor no sólo de la descripción contemporánea de las ruinas, o de romper la relación que se establecía en la época entre los restos de BirsNimrud y el zigurat de Babilonia, posibilidad que, aún mantenida por Rawlinson, Rivadeneyra argumenta en contra de forma correcta, rechazándola como imposible. Narra en el mismo cómo recoge dos ladrillos en el lugar, y cómo los introduce en su mochila. Estos ladrillos hoy se conservan en los almacenes del Museo Arqueológico Nacional, y su tradución y trascripción, así como una introducción a las inscripciones cuneiformes, realizadas todas por Francisco García Ayuso, forman parte del relato. Este es uno de los estudios, realizado por quien ya no ofrecía clases de asirio (y de otras muchas lenguas) en el Madrid de 1871, que nos permiten afirmar que los libros de Rivadeneyra no son sólo libros de viajes, sino que forman un corpus en el que, con el hilo argumental del viaje que está realizando, introduce estudios específicos de lo que hoy consideramos distintas ciencias, y que pretenden introducir el Orientalismo en España, del mismo modo que esta ciencia está naciendo en Europa.

La segunda parte del libro, formada por las cartas y artículos sobre Siria y Ceilán, reproduce cartas que ha enviado a sus padres y amigos o que incluso han sido publicados en la prensa, y que sólo fueron publicados en esta edición de 1871, mientras que sin embargo la primera parte del libro 
se reeditó en 1988 por Laertes (Barcelona). El esquema es similar en toda su obra, bien cuando está de viaje, bien cuando pasa un tiempo en un lugar, Rivadeneyra indaga sobre aspectos etnográficos, religiosos, históricos, artísticos, filológicos..., busca comprender al pueblo que tiene ante sí, también a las personas, y participa de la investigación histórica, afición y dedicación que compatibiliza con su trabajo diplomático.

Sus textos son una mezcla de sensaciones personales del lugar por el que pasa o en el que está residiendo, descripción de lo visto y oído, búsqueda de explicaciones ante las dudas que se le presentan y, sobre todo, la búsqueda del otro tal y como es, sin mayor óptica de superioridad europea.

Esta óptica, que hoy consideramos la óptima, no era necesariamente la habitual en su época, y quizá también por eso los trabajos de Rivadeneyra nos resultan tan atractivos hoy en día. Así (sólo vamos a citar algunos de estos aspectos) en el primer capítulo trata a los Maronitas, también por cierto objeto de estudio de Mentaberry, cuántos son, cómo se distribuyen, cómo es su liturgia, el papel de su clero, el papel de las mujeres en la sociedad, el carácter, el grado de formación..., constituyendo de hecho un completo estudio etnográfico de este pueblo.

Este capítulo viene escrito en el Convento de Ain-warka, es por lo tanto uno de sus primeros trabajos en Oriente, fechado un 27 de mayo de 1864, y dedicado a Antonio Bernal de O'Reilly, su superior, del que ya hemos hablado. Vamos a entresacar una parte del texto, en la que habla de la composición del clero maronita y en qué consiste la liturgia. A Rivadeneyra estos temas le interesan especialmente, y nos hace partícipes en su descripción de sus investigaciones (pp. 238-9, edición de 1871):

El clero maronita se compone de un patriarca (el de Antioquia), trece obispos y seis mil seiscientos entre clérigos y religiosos regulares, distribuidos en cuarenta y cinco conventos rurales ó urbanos. Esta clase es la más instruida; pero su instrucción se reduce al catecismo, á la teología y al cabal conocimiento del árabe; en una palabra, han estudiado el náhu, es decir, la gramática del idioma en su mayor pureza. Algunos hay que, educados en la Propaganda de Roma, se distinguen de los demas por su erudición.

La liturgia de los Maronitas, como la de los griegos católicos y de los armenios, ofrece algunas variantes respecto de la nuestra. La misa, por ejemplo, se dice en siriaco, idioma, como hemos advertido, desusado tiempo há; es más larga y varía un tanto en la forma; el Evangelio, no obstante, se lee en árabe y en alta voz, para que el pueblo lo entienda, y en la comunión se advierte la singular diferencia de que mascan la sagrada forma.

El capítulo séptimo trata sobre la Mezquita de Hebrón, edificio importante entre otras muchas cosas por guardar los sepulcros de Abraham, Isaac y Jacob, y al que prácticamente ningún cristiano había tenido acceso, a causa, según él, del fanatismo de sus habitantes. En su descripción enumera eruditamente distintos autores de la Antigüedad y medievales que han 
tratado el edificio, incluido Ibn-Batuta, quien lo visitó y describió más de quinientos años antes que él. Busca después sus orígenes, y realiza una completísima descripción del edificio, incluyendo trascripciones y traducciones de textos, que le ayudan sin duda a desarrollar mejor sus tesis, pero también a mostrar mejor el templo al lector, haciéndole de algún modo partícipe.

En el texto lo narra sólo en parte, y es que tuvo problemas para entrar en el templo pues no era tal hecho del agrado de la población musulmana, llegándose a montar un tumulto para impedir su entrada, pese a venir invitado por las autoridades. En otro campo hemos de señalar que este incidente le costó un conflicto con su superior, pues mientas éste le reprochaba su falta de celo por el incidente sucedido, el Ministerio le felicitaba por aprovechar las posibilidades de acercamiento, de modo que se vio entre dos frentes, por un lado su superior agraviado, por otro lado felicitado por el ministerio, y creo que él con una sonrisa en los labios pues, pese a todo, pudo contemplar un edificio velado a los cristianos.

De este capítulo vamos a entresacar el párrafo en el que se escucha hablar en castellano y concluyendo que son mujeres judías, señala en nota que «en Oriente, y sobre todo en Constantinopla, Esmirna, Jerusalén y Hebron, hay muchos judíos de origen español, que aún conservan el idioma", es decir, que aporta un nuevo testimonio de los judíos sefardíes. Inmediatamente a estar haciendo este comentario, parece, es requerido para entrar en el templo, y refiere aquí sólo de pasada el conflicto que desencadenó su presencia en el mismo (pp. 307-8):

Hiciéronme entrar por la puerta de la derecha, que mira á una especie de plaza mal alineada; pero, al subir seis anchas gradas semicirculares, reparé en la izquierda cierto número de mujeres que rezaban por turno, poniendo la boca en un pequeño agujero que habia en tierra, en el mismo muro del edificio; y yo, sin pensalo, hube de mirarlas muy de fijo, cuando oi decir en nuestro idioma: "Nos ha topado en devoción y se maravilla." Entonces les dirigí la palabra tambien en castellano, y vine á saber que no pudiendo ellas, por ser judías, entrar en la mezquita, rezaban en el agujero Gaquel, que va á dar al sepulcro de Abraham.

Yo hubiera seguido la conversación con gentes de tan inesperado encuentro; mas el xeque ó administrador del santuario, advertido que habia llegado, mandó abrir la puerta, y al instante me descalcé; entré, siguiéronme dos guardias que traia, y volvieron á cerrarla precipitadamente, quedando fuera buen número del profanum vulgus, maldiciendo á los cristianos y la hora en que habia venido. 
El otro libro que publicó Rivadeneyra, en Madrid, en 1881 y en tres tomos, es su Viaje al interior de Persia. Había sido enviado a la entonces Persia, hoy Irán, para, a través de una legación que se creo al efecto, aprovechar los acuerdos que se habían firmado entre ambos países y, con la misión entre otras, de estudiar las posibilidades comerciales que se podrían abrir a España en aquel país.

Una vez aceptada la misión, buscó asesorarse con el representante persa en París, el general Nazar Aga, previas consultas de la embajada española en Francia. Este sería de hecho la primera etapa de su viaje, y del general obtuvo indicaciones para el viaje, instrucciones de todo tipo, y distintas cartas de recomendación.

En el libro, que como ya hemos dicho vino publicado en tres tomos, creo que pueden verse dos partes, una primera que narra su viaje hasta Teherán, y la gestión de la empresa, el tomo I; y una segunda en la que describe su viaje por Persia, y su posterior regreso a España, los tomos II y III. El material que Rivadeneyra presenta tiene fiel reflejo, al menos una parte del mismo, en documentos que fue enviando al Ministerio. Yo estoy convencido de que el vicecónsul, una vez de regreso de su misión, ya cesado, con un gobierno distinto del que le nombró, y ante la imposibilidad de que le publicasen sus investigaciones tal y como le habían prometido, y que sería parte de su misión (al fin y al cabo iba a abrir caminos para una expansión comercial de España en Persia) decidió publicar él mismo este libro, donde recoge de nuevo multitud de aspectos y temas distintos integrados en un libro de viaje, con el añadido esta vez, de completos estudios que le servirían a cualquier posible comerciante en Irán: trasportes, características de las ciudades, su clima, qué productos comprarían, cuáles venden, aspectos de protocolo y comportamiento...

Como venimos repitiendo, su trabajo diplomático, una viva afición a la búsqueda del conocimiento, al descubrimiento de las personas y de los lugares, de los espacios que descubría y que buscaba recorrer, hicieron de Rivadeneyra un consumado viajero que nos legó sus experiencias a través de múltiples canales.

El recorrido que le llevó de Madrid a Teherán, además de en la parte correspondiente de su Viaje al interior de Persia, lo explicó ampliamente en la "cuenta de los gastos que ha ocasionado su venida a Teherán...", informe que fechó en la capital persa el 15 de mayo de 1874, y que junto a una «Relación del itinerario que ha seguido el Vicecónsul de España en Teherán para trasladarse á su destino", donde lo desarrolla mejor y más extensamente, remitió al Ministerio de Estado, en el cual fue aprobado y en cuyo Archivo se conserva. 


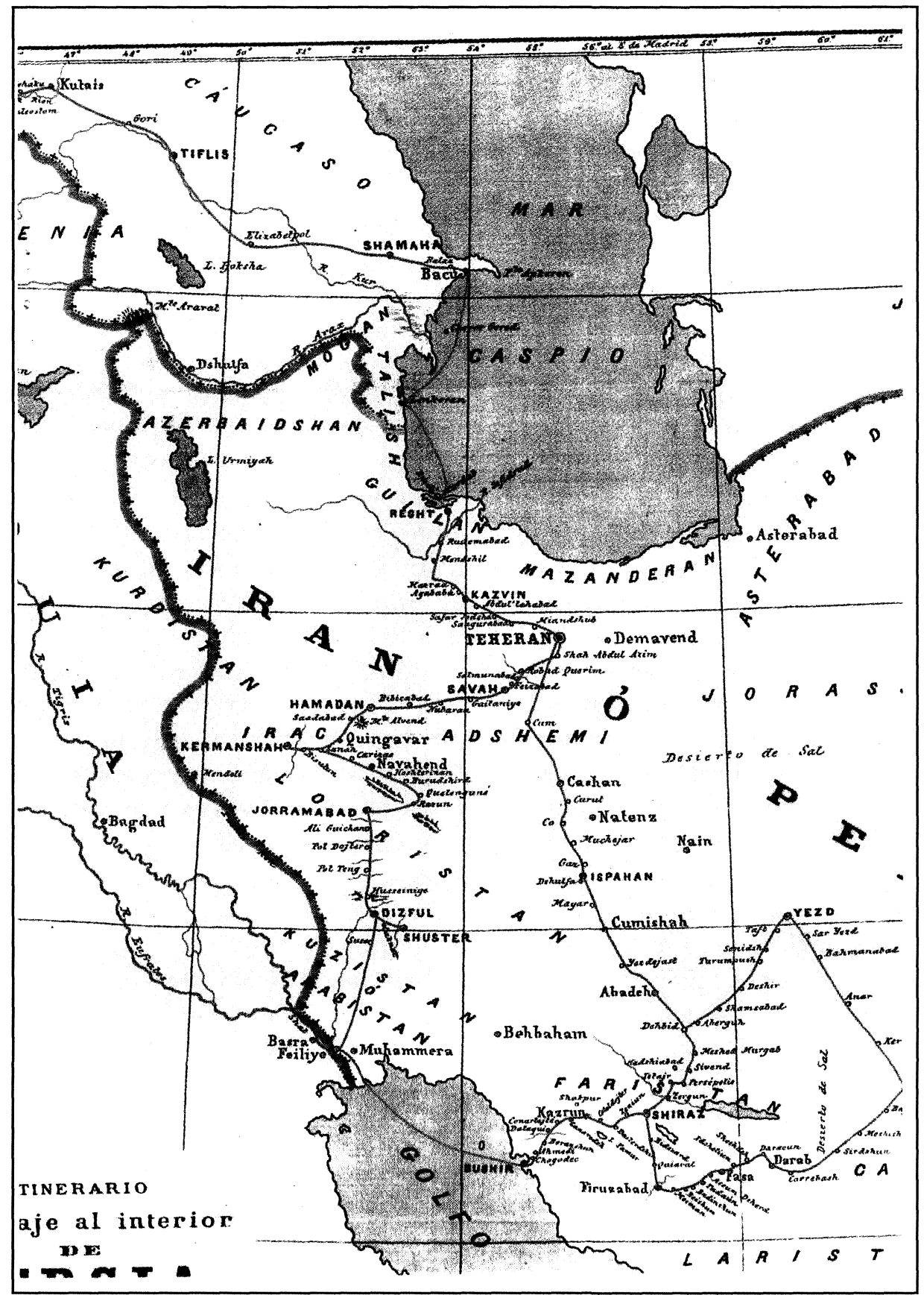

Figura 2. Mapa del itinerario recorrido por Persia que aparece en el volumen III 
El primer documento va explicitando gastos de viajes, estancias y trasportes que hubo de cubrir con el dinero recibido del Gobierno (veinte mil reales, es decir 5.208 francos) desde su salida de Madrid el día 5 de febrero hasta el 11 de abril en que tomó posesión de su destino.

El documento marca cuatro etapas, las mismas que vamos a seguir aquí. El primer destino es París, donde se dirige, como ya hemos contado, tras consultas previas realizadas por personal de la embajada, para entrevistarse con el general Nazar Aga, representante persa ante Francia, en búsqueda de consejos sobre el viaje, para conocer mejor la corte persa, y para obtener cartas de presentación que le ayudasen en su misión, todo lo cual obtuvo. En París permaneció ocho días y de allí, en cinco días, pasando por Viena, donde descansó uno, llegó a Constantinopla. De aquí a Goti, en los vapores de la Compañía rusa de navegación y de comercio, donde finaliza esta primera etapa, y donde pernocta dos noches. De Goti marchó a Tiflis, y hubo de pagar por exceso de equipaje, pues llevaba 112 kilogramos. Hasta Tiflis, final de esta segunda etapa, donde permanece diez días, anota un almuerzo en Kutaïs y una comida en Gori.

Desde Tiflis no pudo realizar un viaje directo hasta Teherán por las barreras de nieve y las temperaturas de 28 grados bajo cero que se lo impedían. Así que hubo de buscar otro itinerario. El viaje de Tiflis a Bacu, tomando sólo la referencia del documento que manejamos, demuestra ser más duro que el precedente. Alejado de rutas organizadas en este trayecto, lo cubre en treinta y dos estaciones, a cuyos treinta y dos cocheros da propinas. Previamente señala la compra de provisiones para el camino, además de una piel de carnero y botas de lo mismo para abrigo en el coche. Entre Elizabelpol y Bacu hubo de contratar caballos extra, e incluso pagar el unto para los ejes del coche. En Bacu permaneció seis días, y hubo de recibir cuatro visitas del médico. Una vez recuperado marchó a Enzeli, final de esta tercera etapa, y donde sólo permaneció un día.

Vamos a entresacar un párrafo de la «Relación del itinerario...» para observar como trabaja Rivadeneyra. En el fondo, este informe tan explícito y detallado que envía al Ministerio no es sólo una descripción extensa del recorrido establecido, o una ampliación que justifique la cuenta de gastos que le acompaña, sino que está dando instrucciones precisas a un posible futuro viajero a Irán sobre el trayecto a elegir, indicando las distintas posibilidades y qué ventajas o inconvenientes puede tener cada una, bien por el tiempo que pueda tardar, bien por las dificultades geográficas o climáticas a superar. 
Va más allá, y habla de los permisos que se deben obtener para recorrer el territorio, dando las distintas posibilidades en función de la condición del viajero, y su costo, de modo que en lo que nosotros vemos hoy como un atractivo relato, se encuentran cumplidas instrucciones necesarias para cualquier viajero, y también para cualquier comerciante.

Descartado pues el camino directo de Tiflis á Teheran, veamos el modo de ir á Bacu, dejando sentado desde luego que en la mayor parte de las vias que cruzan el Cáucaso, y son monopolio del gobierno ruso, no existe servicio regular alguno que permita viajar en tiempo limitado, y por consiguiente sin grandes desembolsos. La persona que pudiera trasladarse de un punto á otro, debe ante todo pedir á las autoridades un documento llamado padarochna, permiso indispensable para tomar el número de caballos que en él se indique, y hasta para entrar en una parada cualquiera.

Lo hay de diferentes clases: el padarochna chazna, o civil, cuesta dos rublos por cada cien verstas, el padarochna cazolnaya ó de la corona, se dá gratis á las personas revestidas de carácter oficial, así nacionales como extranjeras, y tiene sobre el anterior la ventaja de dar preferencia para el cambio de los tiros de caballos; finalmente hay el padarochna de correo, que no solo tiene prioridad sobre el anterior, pero aun da derecho á seis caballos, que los contratistas han de tener expresamente reservados, además de los 24 de que puede disponer el público.

La última etapa le lleva de Enzeli a Geribasar, y de aquí a Recht, en cuyo consulado ruso termina de arreglar documentos. Para marchar de Recht a Teherán alquila cinco caballos y dos sillas de montar, donde llega como hemos citado el 11 de abril, habiendo gastado en total, desde Madrid, cuatro mil ciento veinticuatro francos de los cinco mil doscientos ocho francos confiados por el Gobierno. Y concluye con una especie de resumen que a mí me parece especialmente interesante.

Concretando en breves palabras las consideraciones á que se presta el itinerario de Madrid á la capital de la Persia, convendrá decir, que viniendo en invierno, el término de 58 días es un término sumamente breve: á Tiflis, en verdad, puede llegarse en 22 días, pero de aquí en adelante, es imposible fijar plazo, porque estará siempre sometido á circunstancias imprevistas. En verano, por el contrario, se va cómodamente en un més de Tiflis á Teherán por la vía de tierra, y en muchos menos por la vía de mar, pues entonces las comunicaciones entre Bacu y Enzeli, en vez de ser quincenales, son semanales. Pero en esta misma estación hay otra vía más corta y sobre todo más barata, pues viene á costar la mitad de lo que se gasta atravesando el Caucaso, que es ir en camino de hierro hasta Traritzin, 


\section{Adolfo Rivadeneyra, un diplomático español...}

bajar el Volga hasta Astracan, y de aquí á Enzeli. De la suerte puede venirse desde Madrid á este último puerto en 18 días mediante unos siete mil reales, y habría podido llegarse á Teheran en algunas horas más, á no haberse frustrado, como desgraciadamente parece estarlo, el proyecto de establecer vias férreas desde el Caspio al Golfo Pérsico; mas también es preciso advertir y tenerse muy presente, que este camino, el más corto y el menos caro, lo rehuye casi todo el mundo para no atravesar el fuilan en tiempo del calor, porque entonces es casi seguro caer víctima de las fiebres intermitentes $y$ tifoideas, tan malignas y tan pertinaces, que sus afectos suelen sentirse por espacio de muchos meses y a veces de años.

Tales son, en resumen, las noticias que más se relacionan con la materialidad del viaje de Madrid á la capital del Reino de Irán.

En Teherán, como también hemos ya indicado, permanece cinco meses, que le sirven para aprender el persa, para documentarse sobre el país, su economía y su historia (envía diversos informes al ministerio) y para preparar mejor el viaje que le permitirá cumplir su misión de la mejor forma posible, y que le llevará a recorrer todo el estado iranio según el mapa que él incluyó en el tomo III de su libro y que nosotros reproducimos en este texto.

El relato de Rivadeneyra nos introduce en el mundo que él está viviendo, y le da pie para tratar distintos temas, donde muestra su erudición histórica, su conocimiento de las ciencias que se desarrollan en su época, y también una investigación de campo en aspectos etnográficos. En un episodio en el que narra cómo le intentan vender distintas monedas, y de las que plantea un completo estudio histórico, él narra cómo empieza a tener ya importancia el comercio con antigüedades o supuestas antigüedades, y cómo las mujeres, en este caso judías, han de cumplir las normas estéticas del país (pp. 63-64, tomo II):

Un labrador encontró aquí cerca una pequeña medalla de oro, que vendió á un judía mediante dos arrobas de trigo; que vendió á un judio mediante dos arrobas de trigo; el judio la vendió á un correligionario en cinco tomanes, y éste en diez á un comerciante árabe, de cuyas manos, pasando por otras, fue la medalla a parar al Museo Británico á cambio de muchas guineas. Llegó esto a saberse en Hamadan, y desde entonces, el que encuentra la cosa más insignificante le atribuye el valor de aquella medalla, y para no equivocarse, principian pidiendo doscientos duros.

Al preguntar á mi vendedor el motivo porque andaban tapadas delante de mi las mujeres de la casa, contestó que así lo exigen los persas; pero no tuvo inconveniente en que se descubrieran para que yo las viese, en lo cual sali poco ganancioso. 

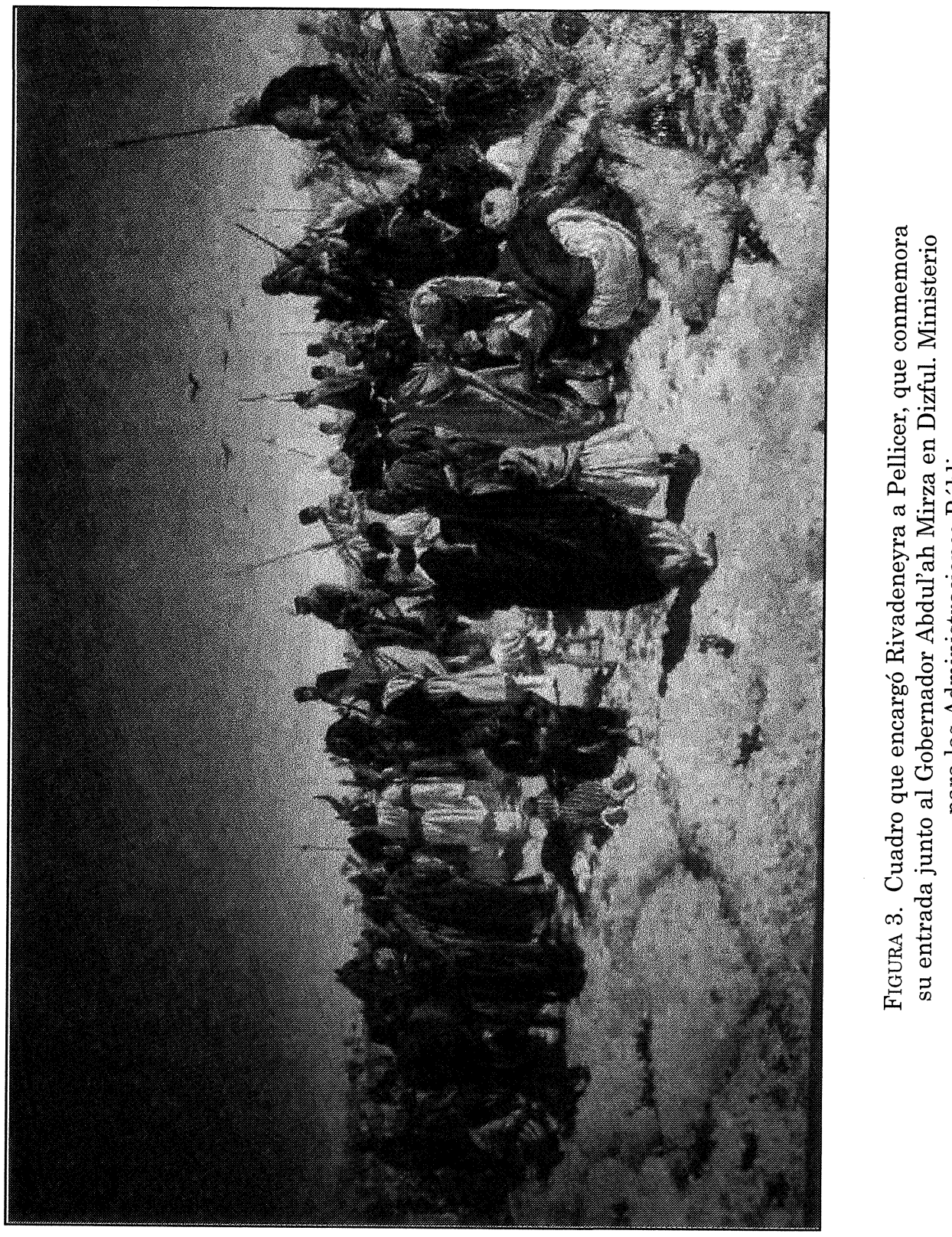
Los aspectos a destacar de un libro tan largo, pero sobre todo tan intenso son miles, y nosotros aquí sólo pretendemos hacer una presentación del autor, del espíritu que gobernaba su viaje, que tiene fiel reflejo en sus libros, siendo sin duda en el propio libro donde el lector va a disfrutar del relato del viajero. A este respecto debemos señalar que sólo está disponible en el mercado la edición de Laertes del primer libro, en cuya reedición completa se está trabajando actualmente, siendo sólo posible encontrar el Viaje al Interior de Persia, y no fácilmente, en el mercado bibliófilo.

Adolfo Rivadeneyra fue un personaje muy destacado en los campos diplomático, orientalista, editorial y cultural de la España del siglo XIX. Sentó las bases de instituciones como la Sociedad Geográfica de Madrid o participó de otras como la Academia de la Historia, en un afán de hacer partícipe a su país del mismo impulso científico que animaba y se extendía por Europa. Pretendió incluso crear una escuela de viajeros españoles que narrasen sus recorridos, de forma que no se tuviese que depender siempre de los textos de viajeros extranjeros, los mismos que traducía su amigo Francisco García Ayuso. Su labor a favor del desarrollo de las ciencias humanistas y del progreso de su país, de forma destacada del Orientalismo, pese a su aparente falta de continuación inmediata, hacen de él un referente destacado para los que hoy continúan su trabajo.

Adolfo Rivadeneyra logró unir su trabajo como diplomático a su amor por el Oriente, fue de hecho también un hombre entre dos mundos, el occidental y el oriental, y desde la óptica del primero intentó trasmitir su amor por el Oriente a sus conciudadanos. Creo que lo consiguió, y lo muestra en sus libros.

\section{Bibliografía}

CóRdoba ZoIlo, J. M. (1998) Del Eufrates y el Tigris a las montañas de Omán. Algunas observaciones sobre viajes, aventuras e investigaciones españolas en Oriente Próximo. Arbor. CLXI, 635-636, 441-463.

CóRDOBA ZoILO, J. M. (2001) La percepción del Irán antiguo y contemporáneo en la obra de los viajeros españoles de los siglos XVII y XIX. Actas del Primer Seminario Monográfico de Primavera. El Redescubrimiento de Oriente Próximo y Egipto. Viajes, hallazgos e investigaciones. Centro Superior de Estudios de Asiriología y Egiptología. Madrid.

EsCRIBANO MARTín, F. (2001) Los estudios sobre Oriente en la España de finales del siglo XIX: la vida y la obra de Francisco García Ayuso. Actas del Primer Seminario Monográfico de Primavera. El Redescubrimiento de Oriente Próximo y Egipto. Centro Superior de Estudios de Asiriología y Egiptología. UAM. Madrid, pp. 107-116. 


\section{Fernando Escribano Martín}

804

ESCRIBANO MARTÍN, F. (1999) Embajadas y viajeros hispanos del siglo XVII al Oriente Próximo. ISIMU. Vol. 2. Centro Superior de Estudios de Asiriología y Egiptología. UAM. Madrid, pp. 95-116.

GARCíA-Romeral PÉREZ, C. (1995) Bío-Bibliografía de viajeros españoles (siglo XIX). Madrid. Ollero y Ramos.

LITVAK, L. (1987)Viaje al interior de Persia. El itinerario de Rivadeneyra.(1874-75). Ediciones del Serval. Barcelona.

Rivadeneyra, A. (1871)Viaje de Ceylan a Damasco. Golfo Pérsico. Mesopotamia. Ruinas de Babilonia, Nínive y Palmira. Madrid 1871.

Este libro tiene dos partes: Viaje de Ceylan a Damasco; y Cartas y artículos sobre la Siria y la Isla de Ceylan. La edición de Laertes sólo recoge la primera:

RivadeneyRA, A. (1986) De Ceilán a Damasco. Laertes. Barcelona.

RIVADENEYRA, A. (1880) Viaje al interior de Persia. Madrid. Imprenta y Estereotipia de Aribau y C $\mathrm{C}^{\mathrm{a}}$. (Sucesores de Rivadeneyra). 3 tomos.

Rodríguez Esteban, J. A. (1996) Geografía y colonialismo. La Sociedad Geográfica de Madrid (1876 - 1936). Madrid.

SAAVEDRA, E. (1883) Discurso en elogio de D. Adolfo Rivadeneyra. Boletín de la Sociedad Geográfica de Madrid, $\mathrm{n}^{\circ}$. XII, pp.495-513. 